\title{
Quantifying the impact of surgical decompression on quality of life and identification of factors associated with outcomes in patients with symptomatic metastatic spinal cord compression
}

\author{
*Asad M. Lak, MD,, Amina Rahimi, BSc, ${ }^{1}$ Abdullah M. Abunimer, MD, ${ }^{1}$ lan Tafel, MD, ${ }^{1}$ \\ Sharmila Devi,, ${ }^{1,2}$ Akash Premkumar, BS, ${ }^{1}$ Fidelia Ida, BPharm, MS, ${ }^{1,3}$ Yi Lu, MD, PhD, ${ }^{1}$ \\ John H. Chi, MD, ${ }^{1}$ Shyam Tanguturi, MD, ${ }^{4}$ Michael W. Groff, MD, ${ }^{1}$ and Hasan A. Zaidi, MD ${ }^{1}$ \\ ${ }^{1}$ Computational Neuroscience Outcomes Center, Department of Neurosurgery, Brigham and Women's Hospital, Harvard \\ Medical School, Boston, Massachusetts; 'Faculty of Life Sciences and Medicine, King's College, London, United Kingdom; \\ ${ }^{3}$ Massachusetts College of Pharmacy and Health Science, Boston; and ${ }^{4}$ Department of Radiation Oncology, Brigham and \\ Women's Hospital, Boston, Massachusetts
}

OBJECTIVE Metastatic spinal cord compression (MSCC) imposes significant impairment on patient quality of life and often requires immediate surgical intervention. In this study the authors sought to estimate the impact of surgical intervention on patient quality of life in the form of mean quality-adjusted life years (QALY) gained and identify factors associated with positive outcomes.

METHODS The authors performed a retrospective chart review and collected data for patients who had neurological symptoms resulting from radiologically and histologically confirmed MSCC and were treated with surgical decompression during the last 12 years.

RESULTS A total of 151 patients were included in this study (mean age 60.4 years, $57.6 \%$ males). The 5 most common metastatic tumor types were lung, multiple myeloma, renal, breast, and prostate cancer. The majority of patients had radioresistant tumors (82.7\%) and had an active primary site at presentation (67.5\%). The median time from tumor diagnosis to cord compression was 12 months and the median time from identification of cord compression to death was 4 months. Preoperative presenting symptoms included motor weakness $(70.8 \%)$, pain $(70.1 \%)$, sensory disturbances (47.6\%), and bowel or bladder disturbance (31.1\%). The median estimated blood loss was $500 \mathrm{~mL}$ and the average length of hospital stay was 10.3 days. About $18 \%$ of patients had postoperative complications and the mean follow-up was 7 months. The mean pre- and postoperative ECOG (Eastern Cooperative Oncology Group) performance status grades were 3.2 and 2.4 , respectively. At follow-up, $58.3 \%$ of patients had improved status, $31.5 \%$ had no improvement, and $10.0 \%$ had worsening of functional status. The mean QALY gained per year in the entire cohort was 0.55 . The mean QALY gained in the first 6 months was 0.1 and in the first year was 0.4 . For patients who lived 1-2, 2-3, 3-4, or 4-5 years, the mean QALY gained were $0.8,1.4,1.7$, and 2.3 , respectively. Preoperative motor weakness, bowel dysfunction, bladder dysfunction, and ASA (American Society of Anesthesiologists) class were identified as independent predictors inversely associated with good outcome.

CONCLUSIONS The mean QALY gained from surgical decompression in the first 6 months and first year equals 1.2 months and 5 months of life in perfect health, respectively. These findings suggest that surgery might also be beneficial to patients with life expectancy $<6$ months.

https://thejns.org/doi/abs/10.3171/2020.1.SPINE191326

KEYWORDS metastatic spinal cord compression; outcomes; quality of life; surgery; oncology

ABBREVIATIONS ASA = American Society of Anesthesiologists; $A S I A=$ American Spinal Injury Association; $D V T=$ deep venous thrombosis; $E B L=$ estimated blood loss; ECOG = Eastern Cooperative Oncology Group; LOS = length of hospital stay; MSCC = metastatic spinal cord compression; PE = pulmonary embolism; QALY = qualityadjusted life years; SINS = Spinal Instability Neoplastic Score.

SUBMITTED November 5, 2019. ACCEPTED January 27, 2020.

INCLUDE WHEN CITING Published online April 3, 2020; DOI: 10.3171/2020.1.SPINE191326.

${ }^{*}$ M.W.G. and H.A.Z. share senior authorship of this work. 
$\mathrm{M}$ ETASTATIC spinal cord compression (MSCC) is a worrisome cause of spinal cord damage which significantly affects patients' ability for self-care. The condition is estimated to affect around $10 \%-20 \%$ of all patients with cancer. Surgical decompression with or without adjuvant postoperative radiation is considered the standard of care. ${ }^{2}$ Given the invasive nature of surgical decompression, it is generally reserved for patients with neurological deficits or spinal instability and life expectancy $>6$ months. ${ }^{3,4}$ The goal of surgery can be curative or palliative depending on patients' overall health condition, primary tumor, prognosis, and goals of care. Surgical decompression provides better outcomes than other treatment modalities, ${ }^{2}$ but there is a paucity of studies that have quantified the improvement in patients' quality of life as a measure of time after surgical intervention, particularly in patients with short follow-up intervals. Additionally, identification of factors associated with better outcomes will help clinicians to decide on the best course of action in these complex patients. Previous studies identified several factors associated with positive outcomes; however, the majority of these studies included neurologically intact patients as well as those who had only radiological signs of cord compression or pain as a presenting symptom. Other studies excluded patients who had radiosensitive tumors, multilevel cord compression, or were deceased at the time of study. $2,4-8$

The goals of our study were to quantify the improvement in quality of life following surgical decompression using the quality-adjusted life years (QALY) and to identify factors associated with better outcomes in patients with true neurological deficits caused by MSCC who were treated with surgical decompression.

\section{Methods \\ Data Acquisition}

After obtaining IRB approval with a waiver of consent, we conducted a multicenter (Brigham and Women's and Massachusetts General Hospital) retrospective analysis of patients with true neurological symptoms, i.e., motor weakness, sensory disturbance, bowel dysfunction, or bladder dysfunction resulting from radiologically and histologically confirmed MSCC and treated surgically over the last 12 years. Exclusion criteria included patients who presented only with pain, i.e., who were neurologically intact despite MSCC; patients who had compression below the L1 vertebral level, i.e., cauda equina compression; patients with spinal cord compression from CNS primary tumors or any other etiology; and patients who were treated nonsurgically.

Patient demographic data, including age; sex; BMI; disease characteristics including primary tumor type, status of primary tumor, and nonspinal metastasis; time interval between primary tumor diagnosis and spinal cord compression; time from spinal cord compression to death; level(s) of cord compression; region of cord compression; presenting signs and symptoms; surgical characteristics, including timing of surgery (immediate, within 24 hours; or delayed, after 24 hours); surgical approach (anterior, posterior, or combined); number of levels operated; es- timated blood loss (EBL); length of hospital stay (LOS); complications; adjuvant postoperative radiation; American Society of Anesthesiologists (ASA) physical status; and follow-up were recorded and analyzed.

The rationale to exclude patients with compression below the L1 vertebral level was based on our intention to look specifically for outcomes in spinal cord compression. The timing of the operation (immediate vs delayed decompression) was decided based on the patient's health status and severity of symptoms and the discretion of the primary surgeon. A multilevel cord compression was defined as cord compression at more than 1 vertebral level, whether it be contiguous or discrete. If patients had more than 1 region of compression, i.e., cervicothoracic or thoracolumbar, the decision was made based on the region with the greater number of vertebral levels involved. If the patient had a history of multiple tumors, the primary tumor was considered to be the one identified from a vertebral biopsy. The status of the primary tumor was classified as "active" if the patient's primary disease or nonspinal metastases were seen to be progressing on recent scans in the previous 1 month before MSCC. If MSCC was the initial manifestation and led to the diagnosis of primary tumor, that was also considered active disease. Patients whose tumors were controlled on treatment were classified as "stable." Histologies such as multiple myeloma, small cell lung cancer, Merkel cell carcinoma, and Ewing's sarcoma were included in the radiosensitive category; the rest were considered radioresistant.

Pre- and postoperative neurological symptoms and functional performance were graded according to the American Spinal Injury Association (ASIA) Impairment Scale and Eastern Cooperative Oncology Group (ECOG) performance scale, respectively. ${ }^{9,10}$ An ECOG grade of 0-2 was considered a good outcome and termed as "improvement," whereas an ECOG grade of 3-5 was considered a poor outcome and termed as either "no improvement" or "worsening" depending on preoperative performance level. The choice of grading scale was made based on using ambulation as a key factor of performance level. Ambulatory status was given importance because previous studies have used ability to walk as the primary endpoint. ${ }^{2,5}$

In order to calculate QALY, the health utilities were determined from the Global Health Cost-Effectiveness Analysis Registry. ${ }^{11}$ For health conditions not specifically mentioned in the registry, the Health Utilities Index was calculated by multiplying the utility index for each condition. ${ }^{12}$ The mean QALY gained for each patient was calculated according to the following formula: QALY gained $=$ (postoperative Health Utilities Index - preoperative Health Utilities Index) $\times$ number of years the patient lived after surgical decompression.

The mean QALY gained per year for each patient group was then calculated by aggregating the mean for individual patients in that particular group. To present QALY gained as a function of time, discounting was utilized where the QALY gained after the first year of surgical decompression were discounted by $3 \%$ for each subsequent year. ${ }^{13}$

Further subgroup analyses for the mean QALY gained within the first year were also done; one subgroup analysis compared QALY gained in patients with radiosensi- 
tive versus radioresistant tumor histology, and another compared patients who had active versus stable primary disease, to see if there were any major differences between different categories.

\section{Statistical Analysis}

Continuous variables were reported as mean \pm SD or median (IQR). Categorical variables were reported as frequency (\%). A univariate logistic regression model was built to look for predictors of good outcomes. Significant variables on univariate analysis were used to build a multivariate regression model. A p value $<0.05$ was considered statistically significant. The statistical analysis was performed using Microsoft Excel and Python 3.4.5.

\section{Results \\ Demographics and Disease Characteristics}

Initially, 220 patients with radiologically and histologically confirmed MSCC were found. We excluded 69 patients as they presented only with pain and were neurologically intact. A total of 151 patients were included in our study (Table 1). The mean age was $60.4 \pm 13.5$ years, and $57.6 \%$ of patients were males. The average BMI was $27.2 \pm 6.25 \mathrm{~kg} / \mathrm{m}^{2}$.

The 5 most common primary tumor types were lung cancer $(18.9 \%)$, multiple myeloma (15.5\%), renal cell cancer $(13.5 \%)$, breast cancer $(12.8 \%)$, and prostate cancer $(10.1 \%)$. Other tumor types were gastrointestinal malignancies $(8.10 \%)$, lymphoma (3.37\%), gynecological tumors $(2.0 \%)$, melanoma (2.0\%), and liposarcoma and squamous cell cancer (1.35\%). Angiosarcoma, adrenal cell cancer, chondrosarcoma, chordoma, epithelioid fibrosarcoma, Ewing's sarcoma, hemangioma, Merkel cell cancer, sarcoma, paraganglioma, penile cancer, and pituitary macroadenoma each constituted $<1 \%$ of primary malignancies.

The majority of patients included in this series had radioresistant tumors $(82.7 \%, \mathrm{n}=124)$. Only $17.2 \%(\mathrm{n}=26$; data were missing for 1 patient) had radiosensitive tumors. The mean Spinal Instability Neoplastic Score (SINS) for all patients was $9.61 \pm 2.16$. Preoperatively, $23.1 \%(n=35)$ patients had undergone radiotherapy to the same spinal levels in the previous 1 month before undergoing surgical decompression. At the time of surgery, $67.5 \%(n=102)$ of patients had progressive primary tumors and were thus considered active, whereas $32 \%(n=48$; data were missing for 1 patient) had stable disease that was controlled by treatment with chemotherapy/radiotherapy or a combination of both.

The median time interval between primary tumor diagnosis and spinal cord compression was 12.0 months (IQR $0.18-60.0$ months). In $67.5 \%(\mathrm{n}=102)$ of patients, there was single-level spinal cord compression, whereas $32.4 \%$ $(n=49)$ of patients had multiple levels of compression. The thoracic spine was the most common region of compression, occurring in $84.7 \%$ of patients, followed by the cervical spine $(9.9 \%)$ and the L1 vertebral level (5.29\%). Preoperatively, $67.5 \%$ of patients were classified as ASA class III, $18.6 \%$ as ASA class II, $13.1 \%$ as ASA class IV, and $0.68 \%$ as ASA class I.

\section{Surgical Characteristics}

Regarding surgical timing, $49.3 \%$ of patients were treated with immediate surgery, whereas $50.6 \%$ were treated with delayed surgery. The most common surgical approach was posterior (used in $90.5 \%$ of patients), followed by the anterior approach $(7.43 \%)$ and the combined anterior-posterior approach (2.0\%). Adjuvant postoperative radiation therapy was administered in $57.0 \%(\mathrm{n}=86)$ of patients, with treatment being deferred primarily due to poor performance status, goals of care, or prior receipt of radiotherapy locally before undergoing surgery. The mean number of operated levels was $4.77 \pm 2.35$, median EBL was $500 \mathrm{~mL}$ (IQR $300-1000 \mathrm{~mL}$ ), and average LOS was $10.3 \pm 7.48$ days. The incidence of postoperative complications in our cohort was $17.8 \%$. Except for 3 complications ( 2 wound infections/dehiscence at the 2-month follow-up and 1 hardware failure at the 3-year follow-up), all complications occurred in the 30-day postoperative period. The most common complications were wound infection/ wound dehiscence, systemic infections, dural tears/CSF leaks, fluid/electrolyte disturbance, deep venous thrombosis (DVT)/pulmonary embolism (PE), excessive blood loss, instrument complications (including hardware failure), and postoperative hematoma causing cord compression (Table 2). The mean follow-up period was 7.0 months (range 0.25-108 months).

\section{Neurological Symptoms and Functional Status}

Preoperative presenting symptoms included motor weakness $(70.8 \%)$, pain $(70.1 \%)$, sensory disturbances $(47.6 \%)$, and bowel or bladder disturbances $(31.1 \%)$. Postoperatively, $23.8 \%$ of patients were reported to have motor weakness, $17.2 \%$ complained of varying degrees of pain, $9.27 \%$ reported having sensory disturbance, and $5.29 \%$ reported bowel or bladder disturbance.

With the ASIA Impairment Scale, most patients were classified as grade D (61.2\%) preoperatively, followed by grade C (23.4\%), grade B (11.0\%), and grade A (4.13\%). Postoperatively, ASIA grade E (53.2\%) was the most common, followed by grade $\mathrm{D}(24.0 \%)$, grade $\mathrm{C}(12.4 \%)$, grade B $(6.56 \%)$, and grade A (3.64\%). In particular, there were 6 patients with preoperative ASIA grade A impairment. Of these 6 patients, 1 patient improved to grade B and another patient improved to grade $\mathrm{D}$; the rest remained as grade A. Similarly, of the 16 patients who presented with ASIA grade B, 7 improved to grade C, 1 patient improved to grade D, 2 improved to grade $\mathrm{E}, 4$ remained as grade $\mathrm{B}$, and 2 patients had no data postoperatively. Regarding the 34 patients who presented with ASIA grade C impairment, 9 patients each improved to grade $\mathrm{D}$ and grade $\mathrm{E}$, 7 remained as grade $\mathrm{C}, 3$ progressed to grade $\mathrm{B}, 1$ progressed to grade A, and 5 patients had no data postoperatively. For patients who presented with ASIA grade D impairment $(n=89), 59$ improved to grade $E, 22$ remained as grade $\mathrm{D}, 3$ patients progressed to grade $\mathrm{C}, 1$ progressed to grade $\mathrm{B}$, and 4 patients had no postoperative data.

The mean pre- and postoperative ECOG functional status grades were $3.2 \pm 0.8$ and $2.4 \pm 1.1$, respectively.

\section{Postoperative Outcomes}

Overall, after surgery $58.3 \%$ of patients were reported 
TABLE 1. Characteristics of patients with symptomatic spinal cord compression secondary to metastatic disease

\begin{tabular}{|c|c|}
\hline Characteristic & Value \\
\hline Age, yrs & $60.4 \pm 13.5$ \\
\hline \multicolumn{2}{|l|}{ Sex } \\
\hline Male & $57.6 \%$ \\
\hline Female & $42.3 \%$ \\
\hline $\mathrm{BMI}, \mathrm{kg} / \mathrm{m}^{2}$ & $27.2 \pm 6.25$ \\
\hline $\begin{array}{l}\text { Time btwn primary tumor diagnosis \& spinal cord } \\
\text { compression, mos }\end{array}$ & $12.0(0.18-60.0)$ \\
\hline \multicolumn{2}{|l|}{ Level of cord compression } \\
\hline Single & $67.5 \%$ \\
\hline Multiple & $32.4 \%$ \\
\hline \multicolumn{2}{|l|}{ Region of cord compression } \\
\hline Cervical & $9.9 \%$ \\
\hline Thoracic & $84.7 \%$ \\
\hline Lumbar (L1 only) & $5.29 \%$ \\
\hline \multicolumn{2}{|l|}{ Primary tumor type } \\
\hline Lung & $18.9 \%$ \\
\hline Multiple myeloma & $15.5 \%$ \\
\hline Renal & $13.5 \%$ \\
\hline Breast & $12.8 \%$ \\
\hline Prostate & $10.1 \%$ \\
\hline Others & $29.2 \%$ \\
\hline Radiosensitive tumor & $17.2 \%$ \\
\hline Radioresistant tumor & $82.7 \%$ \\
\hline \multicolumn{2}{|l|}{ Status of primary site } \\
\hline Active & $67.5 \%$ \\
\hline Stable & $32.0 \%$ \\
\hline \multicolumn{2}{|l|}{ ASA class } \\
\hline 1 & $0.68 \%$ \\
\hline II & $18.6 \%$ \\
\hline III & $67.5 \%$ \\
\hline IV & $13.1 \%$ \\
\hline SINS & $9.61 \pm 2.16$ \\
\hline Preoperative radiation & $23.1 \%$ \\
\hline \multicolumn{2}{|l|}{ Surgical approach } \\
\hline Anterior & $7.43 \%$ \\
\hline Posterior & $90.5 \%$ \\
\hline Combined & $2.0 \%$ \\
\hline \multicolumn{2}{|l|}{ Timing of op } \\
\hline Immediate (w/in 24 hrs) & $49.3 \%$ \\
\hline Delayed (>24 hrs) & $50.6 \%$ \\
\hline Adjuvant postop radiation & $57.0 \%$ \\
\hline $\mathrm{EBL}, \mathrm{mL}$ & $500(300-1000)$ \\
\hline No. of levels operated & $4.77 \pm 2.35$ \\
\hline LOS, days & $10.3 \pm 7.48$ \\
\hline Complications & $17.8 \%$ \\
\hline Follow-up, mos & $7.0 \pm 15.0$ \\
\hline
\end{tabular}

CONTINUED IN NEXT COLUMN »
» CONTINUED FROM PREVIOUS COLUMN

TABLE 1. Characteristics of patients with symptomatic spinal cord compression secondary to metastatic disease

\begin{tabular}{lc}
\hline \multicolumn{1}{c}{ Characteristic } & Value \\
\hline Preop ASIA impairment grade & \\
\hline A & $4.13 \%$ \\
\hline B & $11.0 \%$ \\
\hline C & $23.4 \%$ \\
\hline D & $61.2 \%$ \\
\hline Postop ASIA impairment grade & \\
\hline A & $3.64 \%$ \\
\hline B & $6.56 \%$ \\
\hline C & $12.4 \%$ \\
\hline D & $24.0 \%$ \\
\hline E & $53.2 \%$ \\
\hline ECOG functional status grade & $3.2 \pm 0.8$ \\
\hline Preop & $2.4 \pm 1.1$ \\
\hline Postop & \\
\hline Postop outcome & $58.3 \%$ \\
\hline Improvement & $31.5 \%$ \\
\hline No improvement & $10.0 \%$ \\
\hline Worsening of preop symptoms & \\
\hline Vital status at last follow-up & $47.6 \%$ \\
\hline Alive & $52.3 \%$ \\
\hline Deceased & $(1.37-8.50)$ \\
\hline Time from spinal cord compression to death, mos & \\
\hline Values are presented as percentage of patients, mean + SD or median $(I Q R)$
\end{tabular}

to have improvement, $31.5 \%$ were reported as having no improvement, and $10.0 \%$ had worsening of preoperative functional status.

At presentation, $86.0 \%(\mathrm{n}=130)$ of patients had poor ECOG performance status (grades 3-4). Postoperatively, $54.6 \%(\mathrm{n}=71)$ of these patients reported improvement in functional performance level and transitioned to ECOG grades $0-2,40.0 \%(n=52)$ of patients had no improvement, and $5.38 \%(\mathrm{n}=7)$ reported worsening of functional performance. In contrast, $13.9 \%(\mathrm{n}=21)$ of patients had good preoperative ECOG performance (grades 0-2). Postoperatively, $80.9 \%(n=17)$ of these patients reported ECOG performance grades of 0-2, whereas $19.0 \%(\mathrm{n}=4)$ declined to a poor performance level (ECOG grade 3-5).

\section{Quantifying the Improvement in Quality of Life}

The mean QALY gained in the entire cohort per year was 0.55 (half a year of life in perfect health). The mean QALY gained in the first 6 months after surgical decompression surgery was 0.1 (1.2 months of life in perfect health), while in the first year it was 0.4 (5 months of life in perfect health). In patients who lived 1-2, 2-3,3-4, and $4-5$ years, the mean QALY gained were $0.8,1.4,1.7$, and 2.3 , respectively. In patients who lived more than 5 years, the mean QALY gained was 4.0.

In a subgroup calculation of QALY based on radiation sensitivity of tumors, mean QALY gained in the first 6 
TABLE 2. Complications in patients who underwent surgical decompression for metastatic spinal cord compression

\begin{tabular}{lc}
\hline \multicolumn{1}{c}{ Complication } & No. of Patients \\
\hline Wound infection/dehiscence & 6 \\
\hline Systemic infection & 5 \\
\hline Dural tear/CSF leak & 5 \\
\hline Fluid/electrolyte disturbance & 5 \\
\hline DVT/PE & 3 \\
\hline Excessive blood loss & 3 \\
\hline Instrument complications & 3 \\
\hline Postop hematoma & 1 \\
\hline
\end{tabular}

months for patients with radiosensitive tumors was 0.12 (1.4 months of life in perfect health) and in the first year was 0.2 (2.4 months in perfect health). In patients with radioresistant tumors, mean QALY gained in the first 6 months was 0.13 (1.6 months of life in perfect health), whereas in the first year it was 0.34 (4 months of life in perfect health).

Stratifying by the status of the primary site, the mean QALY gained in first 6 months and the first year of surgical decompression for patients with an active primary site were 0.10 (1.2 months) and 0.35 (4.2 months), respectively. In patients with a stable primary site, the mean QALY gained in the first 6 months and the first year were 0.11 (1.32 months) and 0.42 (5.0 months), respectively.

\section{Predictors of Outcomes}

Univariate analysis indicated that preoperative motor weakness, preoperative bowel or bladder dysfunction, and ASA class were significantly associated with good outcomes postoperatively ( $\mathrm{p} \leq 0.05$; Table 3 ). On multivariate analysis, preoperative motor weakness (OR $0.41,95 \%$ CI -1.73 to $-0.03 ; \mathrm{p}=0.04$ ), preoperative bowel or bladder dysfunction (OR $0.36,95 \% \mathrm{CI}-1.77$ to $-0.24 ; \mathrm{p}=0.01$ ), and ASA class (OR $0.47,95 \% \mathrm{CI}-1.39$ to $-0.09 ; \mathrm{p}=0.02$ ) remained significantly associated with postoperative outcomes (Table 4 and Figs. 1-3).

\section{Survival Data}

There were 130 patients for whom data were available regarding vital status. At the last follow-up, 52.3\% ( $\mathrm{n}=$ $68)$ of patients were deceased, and $63.2 \%(n=43)$ of them died within 6 months of surgical intervention. The median time from spinal cord compression to death was 4.0 months (IQR 1.37-8.50 months).

\section{Discussion}

Decision-making in surgical decompression for MSCC is an interplay of the ethical principles of "beneficence" and "nonmaleficence." The goals of treatment include adequate decompression of the spinal cord, stabilization of the spine, and local tumor control. ${ }^{4,8}$ The decision to operate is influenced by the patients' expected survival, general health condition, and probability of neurological recovery if subject to an extensive spine surgery. ${ }^{2,14,15}$ A knowledge
TABLE 3. Univariate analysis results for predictors of good functional outcomes postoperatively

\begin{tabular}{lll}
\hline & \multicolumn{1}{c}{$95 \% \mathrm{Cl}$} & $\mathrm{p}$ Value \\
\hline Age & -0.01 to 0.03 & 0.5 \\
\hline Sex & -1.27 to 0.07 & 0.08 \\
\hline Time between primary tumor \& MSCC & -0.00 to 0.00 & 0.69 \\
\hline Preop motor weakness & -1.96 to -0.35 & $\mathbf{0 . 0 0 5}$ \\
\hline Preop sensory disturbance & -1.10 to 0.20 & 0.18 \\
\hline Preop bowel \& bladder disturbance & -1.52 to -0.11 & 0.02 \\
\hline Timing of surgery & -0.53 to 0.79 & 0.69 \\
\hline Blood loss & -0.00 to 0.00 & 0.20 \\
\hline Length of stay & -0.03 to 0.05 & 0.74 \\
\hline ASA class & -1.38 to -0.10 & 0.02 \\
\hline SINS & -0.04 to 0.26 & 0.15 \\
\hline Status of primary site & -1.09 to 0.32 & 0.29 \\
\hline Radiosensitive histology & -0.34 to 1.47 & 0.22 \\
\hline Boldace type indicates statistica & &
\end{tabular}

Boldface type indicates statistical significance.

of factors associated with outcomes as well as an estimate of improvement in a patient's quality of life can assist surgeons in the decision-making and counseling of patients and their families. In our study of patients presenting with varying degrees of neurological dysfunction as a consequence of MSCC, a majority of the patients reported improvement in their neurological and performance status following surgical decompression. In order to quantify the improvement in the quality of life as a measure of time, we utilized QALY analysis and found a direct correlation between QALY gained and number of years the patient lived after surgery (Fig. 4). We were also able to identify preoperative motor weakness, preoperative bowel or bladder dysfunction, and ASA class as independent factors related to a lesser chance of better functional outcomes postoperatively.

Historically, MSCC has been treated with corticosteroids and radiotherapy due to presumed superior outcomes with these treatment modalities. ${ }^{16,17}$ However, in a landmark randomized controlled trial by Patchell et al., ${ }^{2}$ surgery with postoperative radiotherapy drastically improved outcomes and survival over radiotherapy alone. Moreover, Ghogawala et al. ${ }^{7}$ showed that preoperative radiotherapy was associated with increased complications, and therefore surgical decompression should be the standard treatment of choice with or without postoperative radiotherapy.

Preoperative clinical status was the strongest predic-

TABLE 4. Multivariate analysis results for predictors of good functional outcomes postoperatively

\begin{tabular}{lccc}
\hline & OR & $95 \% \mathrm{Cl}$ & $\mathrm{p}$ Value \\
\hline Age & 1.02 & -0.00 to 0.04 & 0.13 \\
\hline Preop motor weakness & 0.41 & -1.73 to -0.03 & $\mathbf{0 . 0 4}$ \\
\hline Preop bowel or bladder disturbance & 0.36 & -1.77 to -0.24 & $\mathbf{0 . 0 1}$ \\
\hline ASA class & 0.47 & -1.39 to -0.09 & $\mathbf{0 . 0 2}$ \\
\hline
\end{tabular}

Boldface type indicates statistical significance. 


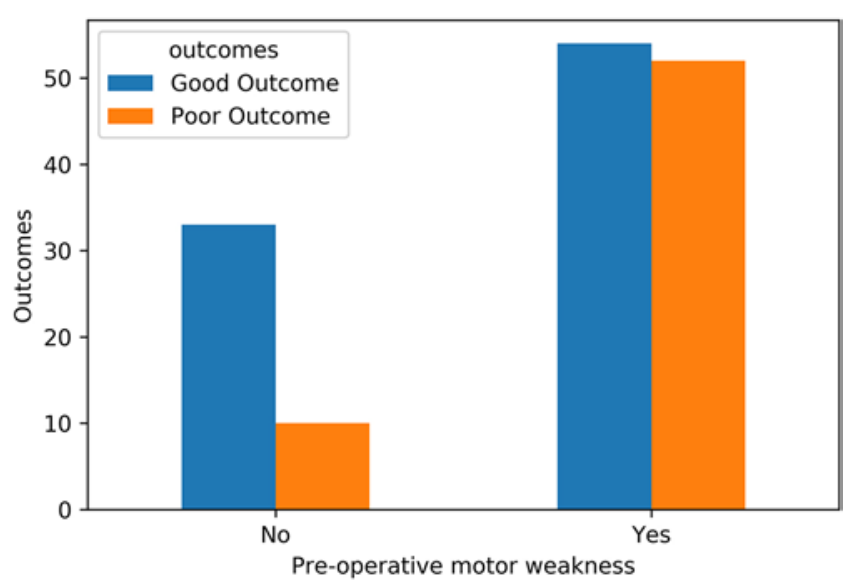

FIG. 1. Bar plot showing proportion of good and poor outcomes in patients with and without motor weakness preoperatively. Figure is available in color online only.

tor of postoperative outcomes. Patients who had poor performance status preoperatively were less likely to attain a good performance status as compared to patients who had good performance status at presentation (54.2\% vs $80.9 \%$ ). These findings are congruent with prior literature that demonstrated the correlation of preoperative neurological and functional performance to postoperative outcomes. ${ }^{5,15,18}$ The proposed pathophysiology for spinal cord compression is that the tumor causes direct compression on the spinal cord, resulting in edema, venous congestion, and demyelination. However, this injury can be reversed if the cord is decompressed adequately before compression leads to infarction and permanent damage. ${ }^{19}$ The relationship of the degree of cord compression to neurological dysfunction has also been manifested in traumatic spinal cord injury: ${ }^{20}$ hence it can be postulated that patients with better functional status preoperatively had lesser degrees of cord compression or irreversible neurological injury, which led to better outcomes postoperatively.

Our study was able to identify the direct correlation of

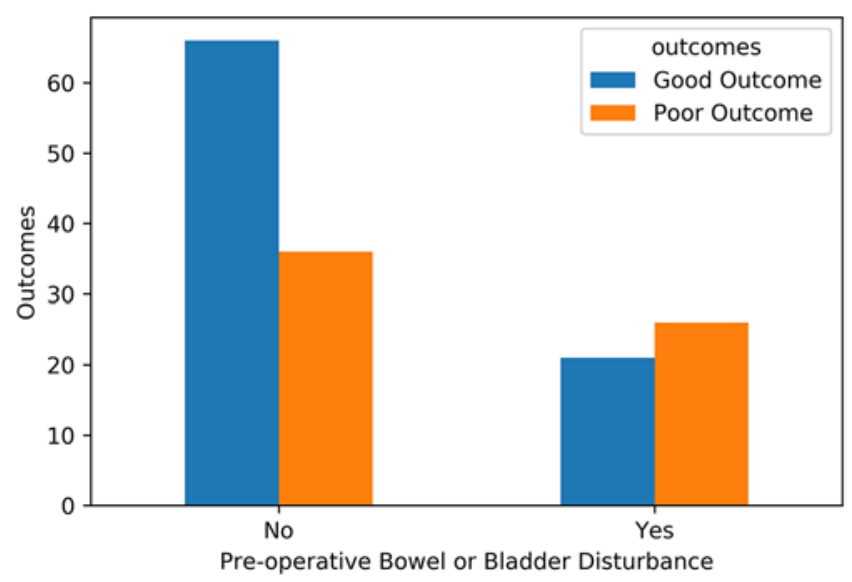

FIG. 2. Bar plot showing proportion of good and poor outcomes in patients with and without bowel and bladder disturbance preoperatively. Figure is available in color online only.

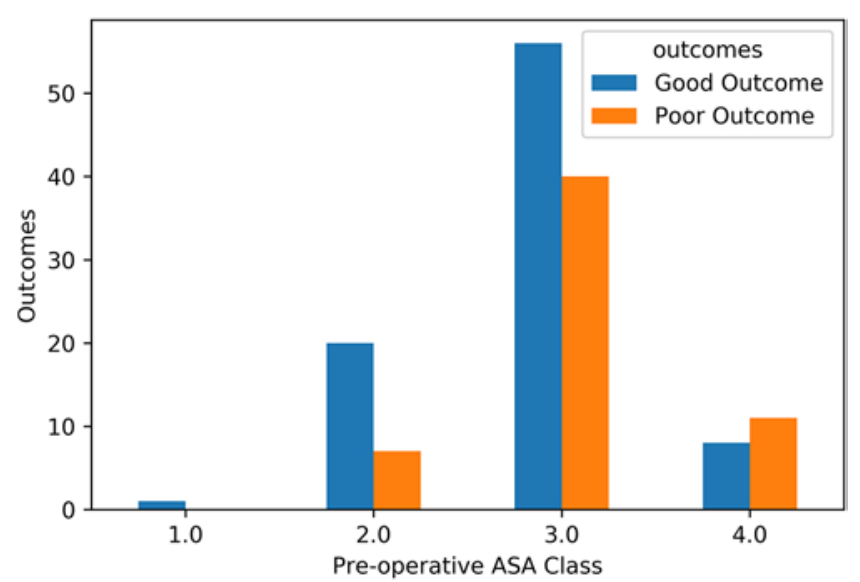

FIG. 3. Bar plot showing proportion of good and poor outcomes in patients among different ASA classes preoperatively. Figure is available in color online only.

improvement in quality of life with the number of years the patient lived after surgery. The mean QALY gained in patients who lived $<6$ months was 0.1 (1.2 months of life in perfect health). This contrasts with a previous study that showed that patients who were treated surgically and lived $<6$ months had worsening of their health status. ${ }^{21}$ A recently published study found that survival did not influence the quality of life following surgical decompression and patient's performance status should be given precedence in decision-making. ${ }^{22}$ This, combined with our study, which also found that surgical decompression can positively induce quality of life even in short-lived patients, indicates that the current recommendations that advise against surgical intervention for patients with estimated life expectancy $<6$ months need further debate.

The identification of several independent factors associated with postoperative outcomes further highlights the importance of surgery as a first-line treatment. Prior literature has demonstrated an increased risk of complications and the need for extensive surgery in nonambulatory patients who already have a decreased likelihood of regaining ambulation compared to ambulatory patients. ${ }^{5}$ Though in our study patients who were treated with immediate surgery versus those treated with delayed surgery had no difference in terms of postoperative outcomes, the identification of motor weakness and bowel or bladder dysfunction as independent predictors of outcome may be indirectly related to the fact that these patients should be offered early surgery before the development of worse neurological symptoms. ${ }^{5,23,24}$ ASA class, which is used to denote the general medical complexity of a patient, ${ }^{25}$ was also found to be inversely associated with a favorable outcome. This also suggests that surgery should be offered immediately, before the patient develops further disease progression, worsening of general health status, and thus diminished chances of recovery.

The median time to death after surgical decompression in our series was 4.0 months. The ability of surgical decompression to attain a better performance level (13.2\% preoperatively vs $45.5 \%$ postoperatively) in patients who were deceased at the last follow-up highlights the impor- 


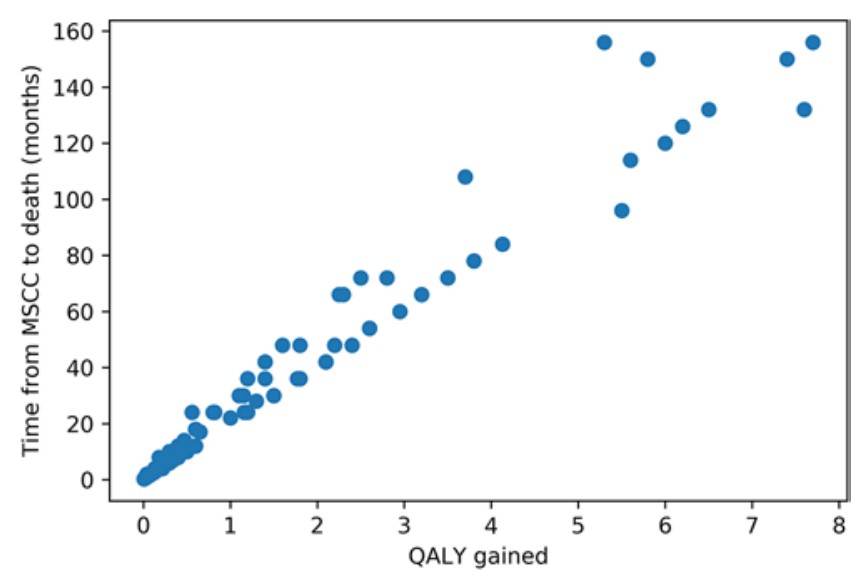

FIG. 4. Relationship of mean QALY gained with the number of years the patient lived after surgery. Figure is available in color online only.

tance of attaining a better quality of life in the last few months of life, even though it does not impact survival. A good performance level is associated with higher quality of life; therefore, attaining the ability of self-care is important in both curative and palliative surgery. 4,6

\section{Study Limitations and Strengths}

This study should be interpreted with consideration of its limitations. This was a retrospective study and is subject to bias. Because the outcomes were recorded from surgeons' follow-up charts, there is potential for underreporting. There can be differences in outcomes based on primary tumor histology, surgical skills, and surgical decision-making. Tumor histology was broadly classified into radiosensitive and radioresistant, and differences in specific tumor types were not taken into consideration as the goal of the study was to look at the outcomes following surgical decompression for all metastatic lesions. To minimize the influence of time on QALY, we utilized the method of discounting. We believe this series is important because we only included patients presenting with true neurological deficits from MSCC and tried to give a broad overview of surgical outcomes. We also believe that utilizing QALY analysis for quantification of improvement in quality of life can facilitate decision-making and counseling.

\section{Conclusions}

Surgical decompression provides considerable chances of neurological recovery and good functional performance in patients presenting with neurological deficits from MSCC. The mean QALY gained correlates with the number of years the patient lives and we conclude that surgery can be beneficial to patients with a shorter life expectancy. The guidelines which recommend against surgery for short-lived patients need to be debated further. Moreover, the presence of preoperative motor weakness, bowel or bladder dysfunction, and poor physical status determined by ASA class were found to be negatively associated with a good outcome.

\section{References}

1. Klimo P Jr, Thompson CJ, Kestle JR, Schmidt MH. A metaanalysis of surgery versus conventional radiotherapy for the treatment of metastatic spinal epidural disease. Neuro Oncol. 2005;7(1):64-76.

2. Patchell RA, Tibbs PA, Regine WF, et al. Direct decompressive surgical resection in the treatment of spinal cord compression caused by metastatic cancer: a randomised trial. Lancet. 2005;366(9486):643-648.

3. Bilsky M, Smith M. Surgical approach to epidural spinal cord compression. Hematol Oncol Clin North Am. 2006;20(6):1307-1317.

4. Hohenberger C, Schmidt C, Höhne J, et al. Effect of surgical decompression of spinal metastases in acute treatment-predictors of neurological outcome. J Clin Neurosci. 2018;52:7479.

5. Chaichana KL, Woodworth GF, Sciubba DM, et al. Predictors of ambulatory function after decompressive surgery for metastatic epidural spinal cord compression. Neurosurgery. 2008;62(3):683-692.

6. de Ruiter GC, Nogarede CO, Wolfs JF, Arts MP. Quality of life after different surgical procedures for the treatment of spinal metastases: results of a single-center prospective case series. Neurosurg Focus. 2017;42(1):E17.

7. Ghogawala Z, Mansfield FL, Borges LF. Spinal radiation before surgical decompression adversely affects outcomes of surgery for symptomatic metastatic spinal cord compression. Spine (Phila Pa 1976). 2001;26(7):818-824.

8. Wang JC, Boland P, Mitra N, et al. Single-stage posterolateral transpedicular approach for resection of epidural metastatic spine tumors involving the vertebral body with circumferential reconstruction: results in 140 patients. Invited submission from the Joint Section Meeting on Disorders of the Spine and Peripheral Nerves, March 2004. J Neurosurg Spine. 2004;1(3):287-298.

9. de Borja MT, Chow E, Bovett G, et al. The correlation among patients and health care professionals in assessing functional status using the Karnofsky and Eastern Cooperative Oncology Group performance status scales. Support Cancer Ther. 2004;2(1):59-63.

10. Roberts TT, Leonard GR, Cepela DJ. Classifications in brief: American Spinal Injury Association (ASIA) Impairment Scale. Clin Orthop Relat Res. 2017;475(5):1499-1504.

11. The Cost-Effectiveness Analysis Registry. Center for the Evaluation of Value and Risk in Health. www.cearegistry.org. Accessed February 13, 2020.

12. Naglie G, Krahn MD, Naimark D, et al. Primer on medical decision analysis: Part 3-Estimating probabilities and utilities. Med Decis Making. 1997;17(2):136-141.

13. Attema AE, Brouwer WBF, Claxton K. Discounting in economic evaluations. Pharmacoeconomics. 2018;36(7):745758.

14. Nater A, Tetreault LA, Kopjar B, et al. Predictive factors of survival in a surgical series of metastatic epidural spinal cord compression and complete external validation of 8 multivariate models of survival in a prospective North American multicenter study. Cancer. 2018;124(17):3536-3550.

15. Putz C, van Middendorp JJ, Pouw MH, et al. Malignant cord compression: a critical appraisal of prognostic factors predicting functional outcome after surgical treatment. J Craniovertebr Junction Spine. 2010;1(2):67-73.

16. Gilbert RW, Kim JH, Posner JB. Epidural spinal cord compression from metastatic tumor: diagnosis and treatment. Ann Neurol. 1978;3(1):40-51.

17. Loblaw DA, Perry J, Chambers A, Laperriere NJ. Systematic review of the diagnosis and management of malignant extradural spinal cord compression: the Cancer Care Ontario Practice Guidelines Initiative's Neuro-Oncology Disease Site Group. J Clin Oncol. 2005;23(9):2028-2037. 
18. Helweg-Larsen S, Sørensen PS, Kreiner S. Prognostic factors in metastatic spinal cord compression: a prospective study using multivariate analysis of variables influencing survival and gait function in 153 patients. Int J Radiat Oncol Biol Phys. 2000;46(5):1163-1169.

19. Thomas N, Byrne ECB, Waxman SG. Diseases of the Spine and Spinal Cord. Oxford, England: Oxford University Press; 2000.

20. Skeers P, Battistuzzo CR, Clark JM, et al. Acute thoracolumbar spinal cord injury: relationship of cord compression to neurological outcome. J Bone Joint Surg Am. 2018;100(4):305-315.

21. Morgen SS, Engelholm SA, Larsen CF, et al. Health-related quality of life in patients with metastatic spinal cord compression. Orthop Surg. 2016;8(3):309-315.

22. Dea N, Versteeg AL, Sahgal A, et al. Metastatic spine disease: should patients with short life expectancy be denied surgical care? An international retrospective cohort study [published online November 6, 2019]. Neurosurgery. doi:10.1093/neuros/nyz472

23. Fürstenberg CH, Wiedenhöfer B, Gerner HJ, Putz C. The effect of early surgical treatment on recovery in patients with metastatic compression of the spinal cord. J Bone Joint Surg Br. 2009;91(2):240-244.

24. Quraishi NA, Rajagopal TS, Manoharan SR, et al. Effect of timing of surgery on neurological outcome and survival in metastatic spinal cord compression. Eur Spine J. 2013;22(6):1383-1388.

25. American Society of Anesthesiologists. New classification of physical status. Anesthesiology. 1963;24:111.

\section{Disclosures}

Dr. Groff reports receiving royalties from DePuy Spine, Biomet Spine, NuVasive, and SpineArt.

\section{Author Contributions}

Conception and design: Zaidi, Lak, Tafel, Lu, Chi, Tanguturi, Groff. Acquisition of data: Lak, Rahimi, Abunimer, Devi, Premkumar. Analysis and interpretation of data: Zaidi, Lak, Rahimi, Abunimer, Tafel, Devi, Premkumar, Ida, Lu, Chi, Tanguturi. Drafting the article: Zaidi, Lak, Rahimi, Abunimer, Tafel, Devi, Premkumar, Ida, Tanguturi. Critically revising the article: Zaidi, Lak, Rahimi, Abunimer, Tafel, Ida, Lu, Chi, Tanguturi, Groff. Reviewed submitted version of manuscript: all authors. Approved the final version of the manuscript on behalf of all authors: Lak. Statistical analysis: Lak, Abunimer, Ida. Study supervision: Zaidi, Lu, Chi, Tanguturi, Groff.

\section{Supplemental Information}

\section{Previous Presentations}

Parts of this manuscript were presented as an oral presentation at the AANS/CNS Annual Section Meeting on Disorders of Spine and Peripheral Nerves, Las Vegas, NV, March 5-8, 2020, and were accepted as a poster presentation at the 2020 AANS Annual Meeting.

\section{Correspondence}

Hasan A. Zaidi: Brigham and Women's Hospital, Harvard Medical School, Boston, MA. hzaidi1@bwh.harvard.edu. 